Journal of Biotechnology and Strategic Health Research

\author{
Research Article / Araştırma Makalesi
}

http://dergipark.org.tr/tr/pub/bshr

\title{
İki Farklı Hidrojen Peroksit Gaz Plazma Sterilizatörünün Lümenli Tıbbi Cihazlardaki Performanslarının Değerlendirilmesi
}

\author{
Evaluation of The Performance Of Two Different Hydrogen Peroxide Gas Plasma \\ Sterilizers in Lumenic Medical Devices
}

\section{(D) $\triangle$ Mustafa Altay Atalay ${ }^{1}$, (D) Meral Altakhan², (D) Pınar Sağıroğlu'}

${ }^{1}$ Erciyes Üniversitesi Tip Fakültesi, Tibbi Mikrobiyoloji Anabilim Dalı, Kayseri

${ }^{2}$ Erciyes Üniversitesi Tip Fakültesi, Merkezi Sterilizasyon Ünitesi, Kayseri

ORCID ID: Mustafa Altay Atalay, https://orcid.org/0000-0003-4169-0637, Meral Altakhan, https://orcid.org/0000-0003-3859-1638

Pınar Sağıroğlu, https://orcid.org/0000-0001-6742-0200

^Sorumlu Yazar / Corresponding Author: Mustafa Altay Atalay, e-posta / e-mail: altayatalay@gmail.com

Geliş Tarihi / Received: 22-09-2020 Kabul Tarihi / Accepted: 18-10-2020 Yayın Tarihi / Online Published: 31-12-2020

Atıf Gösterimi/How to Cite: Atalay M.A., Altakhan M., Sağıroğlu P. İki Farklı Hidrojen Peroksit Gaz Plazma Sterilizatörünün Lümenli Tibbi Cihazlardaki Performanslarının Değerlendirilmesi, J Biotechnol and Strategic Health Res. 2020;4(3):272-276

Çalışma kısmi olarak 38. Türk Mikrobiyoloji Cemiyeti kongresi 2018’de PS 266 olarak sunulmuştur.

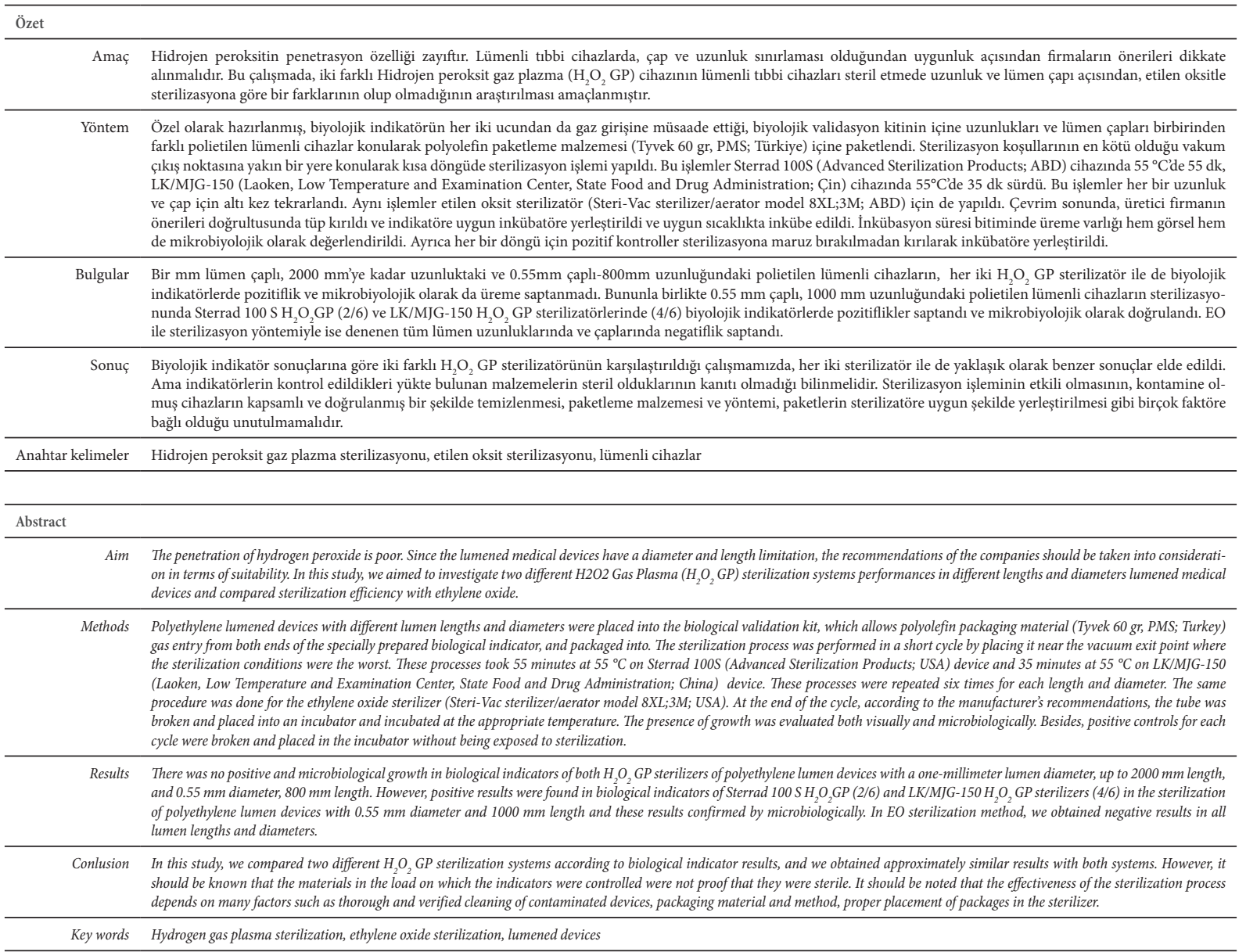




\section{GIIRIŞ}

Hidrojen peroksit gaz plazma $\left(\mathrm{H}_{2} \mathrm{O}_{2} \mathrm{GP}\right)$ sistemi ile sterilizasyon yöntemi, hızlı, güvenli, toksik kalıntı bırakmayan, ısıya ve neme duyarlı malzemeler için etkin bir sterilizasyon yöntemidir. Çok sayıda tıbbi cihaz için kullanılmaktadır. Ancak selülozik materyal (kağıt ve bez), pudra, sıvıların sterilizasyonu için önerilmemektedir. ${ }^{1}$ Hidrojen peroksitin penetrasyon özelliği zayıftır. Lümenli tıbbi cihazlarda çap ve uzunluk sınırlaması olduğundan, uygunluğu konusunda firmanın önerileri dikkate alınmalıdır. ${ }^{2}$ Etilen Oksit (EO) ile sterilizasyon yöntemi de sıcaklığa duyarlı malzemeler ve lümenli aletler için tercih edilir. Öte yandan EO ile sterilizasyonda, sterilizasyon ve havalandirma süresi uzundur. EO; toksik, kanserojen, yanıcı ve patlayıcı bir gazdır. ${ }^{3}$

Bu çalışmada, iki farklı H2O2 GP cihazının lümenli tıbbi cihazları steril etmede uzunluk ve lümen çapı açısından, EO ile sterilizasyona göre bir farklarının olup olmadığının araştırılması amaçlanmıştır.

\section{YÖNTEM}

Özel olarak hazırlanmış, biyolojik indikatörün her iki ucundan da gaz girişine müsaade ettiği, biyolojik validasyon kitinin (Full Care; Çin) (Resim 1) içine uzunlukları ve lümen çapları sırasıyla; 4000 mm-1 mm (2000 mm biyolojik indikatörün bir ucuna, $2000 \mathrm{~mm}$ diğer ucuna gelecek şekilde), 3000 mm-1 mm (1500 mm biyolojik indikatörün bir ucuna, $1500 \mathrm{~mm}$ diğer ucuna gelecek şekilde), 2000 $\mathrm{mm}-0.55 \mathrm{~mm}$ (1000 mm biyolojik indikatörün bir ucuna, $1000 \mathrm{~mm}$ diğer ucuna gelecek şekilde ve $1600 \mathrm{~mm}-0.55$ $\mathrm{mm}$ ( $800 \mathrm{~mm}$ biyolojik indikatörün bir ucuna, $800 \mathrm{~mm}$ diğer ucuna gelecek şekilde) olan polietilen lümenli cihazlar konularak polyolefin paketleme malzemesi (Tyvek 60 gr, PMS; Türkiye) içine paketlendi ve sterilizasyon koşullarının en kötü olduğu vakum çıkış noktasına yakın bir yere konularak kısa döngüde sterilizasyon işlemi yapıldı. Bu işlemler Sterrad 100S (ABD) cihazında $55^{\circ} \mathrm{C}$ 'de $55 \mathrm{dk}$, Laoken, LK/MJG-150 (Çin) cihazında $55^{\circ} \mathrm{C}$ 'de $35 \mathrm{dk}$ sürdü. $\mathrm{Bu}$ işlemler her bir uzunluk ve çap için altı kez tekrarlandı.

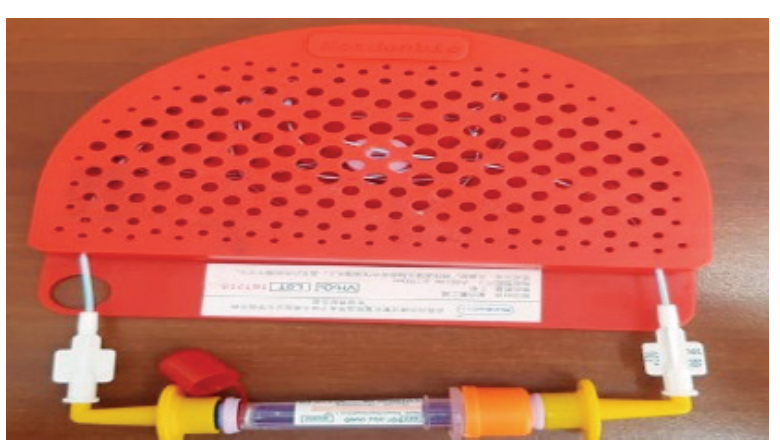

Resim 1. Biyolojik indikatörün her iki ucundan da gaz girişine müsaade ettiği, biyolojik validasyon kiti

Aynı işlemler etilen oksit sterilizatör (Steri-Vac sterilizer/ aerator model 8XL;3M; ABD) için de yapıldı. Çevrim sonunda, üretici firmanın önerileri doğrultusunda tüp kırıl$\mathrm{d}_{1}$ ve indikatöre uygun inkübatöre yerleştirildi ve uygun sıcaklıkta inkübe edildi. İnkübasyon süresi bitiminde üreme varlığı değerlendirildi. Ayrıca her bir döngü için pozitif kontroller sterilizasyona maruz birakılmadan kırılarak inkübatöre yerleştirildi.

Mikrobiyoloji laboratuvarında da ekim işlemleri yapılarak biyolojik indikatörler ve pozitif kontroller değerlendirildi. Bunun için; indikatörün içindeki spor taşıyıcı stripler ç1karıldı, steril tüplere yerleştirildi ve her tüpe $0.6 \mathrm{~mL}$ steril distile su konuldu, mekanik olarak karıştırıldı ve üzerlerine $0,4 \mathrm{~mL}$ etanol eklenerek tekrar karıştırıldı, iki saat oda 1sısında bekletildi ve sonrasinda $80-85^{\circ} \mathrm{C}$ suya konuldu ve $15 \mathrm{dk}$ bekletildi, buradan alınarak $+4{ }^{\circ} \mathrm{C}$ deki soğuk suya batırıld, triptik soy broth ve $\% 5$ koyun kanlı agar besiyerlerine ekimleri yapıldı, $60^{\circ} \mathrm{C}$ ’ye ayarlanmıs etüvde inkübe edildi.

\section{BULGULAR}

Bir mm lümen çaplı, 2000 mm'ye kadar uzunluktaki ve $0.55 \mathrm{~mm}$ çapl1-800mm uzunluğundaki polietilen lümenli cihazların, her iki H2O2 GP ile de biyolojik indikatörlerde pozitiflik ve mikrobiyolojik olarak da üreme saptanmadı. Bununla birlikte $0.55 \mathrm{~mm}$ çaplı, $1000 \mathrm{~mm}$ uzunluğundaki polietilen lümenli cihazların sterilizasyonunda Sterrad 100 
J Biotechnol and Strategic Health Res. 2020;4(3):272-276

ATALAY, ALTAKHAN, SAĞIROĞLU, Lümenli aletlerde $\mathrm{H}_{2} \mathrm{O}_{2}$ gaz plazma sterilizasyonu

\begin{tabular}{|c|c|c|c|}
\hline Uzunluk-Lümen Çapı & Sterrad $100 \mathrm{~S} \mathrm{H}_{2} \mathrm{O}_{2} \mathrm{GP}$ & Laoken $\mathrm{H}_{2} \mathrm{O}_{2} \mathrm{GP}$ & Etilen Oksit \\
\hline $1500 \mathrm{~mm}-1 \mathrm{~mm}$ & $\mathrm{~N} / \mathrm{N} / \mathrm{N} / \mathrm{N} / \mathrm{N} / \mathrm{N}$ & $\mathrm{N} / \mathrm{N} / \mathrm{N} / \mathrm{N} / \mathrm{N} / \mathrm{N}$ & $\mathrm{N} / \mathrm{N} / \mathrm{N} / \mathrm{N} / \mathrm{N} / \mathrm{N}$ \\
\hline $2000 \mathrm{~mm}-1 \mathrm{~mm}$ & $\mathrm{~N} / \mathrm{N} / \mathrm{N} / \mathrm{N} / \mathrm{N} / \mathrm{N}$ & $\mathrm{N} / \mathrm{N} / \mathrm{N} / \mathrm{N} / \mathrm{N} / \mathrm{N}$ & $\mathrm{N} / \mathrm{N} / \mathrm{N} / \mathrm{N} / \mathrm{N} / \mathrm{N}$ \\
\hline $800 \mathrm{~mm}-0.55 \mathrm{~mm}$ & $\mathrm{~N} / \mathrm{N} / \mathrm{N} / \mathrm{N} / \mathrm{N} / \mathrm{N}$ & $\mathrm{N} / \mathrm{N} / \mathrm{N} / \mathrm{N} / \mathrm{N} / \mathrm{N}$ & $\mathrm{N} / \mathrm{N} / \mathrm{N} / \mathrm{N} / \mathrm{N} / \mathrm{N}$ \\
\hline $1000 \mathrm{~mm}-0.55 \mathrm{~mm}$ & $\mathbf{P} / \mathrm{N} / \mathrm{N} / \mathbf{P} / \mathrm{N} / \mathrm{N}$ & $\mathbf{P} / \mathbf{P} / \mathrm{N} / \mathbf{P} / \mathbf{P} / \mathrm{N}$ & $\mathrm{N} / \mathrm{N} / \mathrm{N} / \mathrm{N} / \mathrm{N} / \mathrm{N}$ \\
\hline
\end{tabular}

S H2O2GP (2/6) ve LK/MJG-150 H2O2 GP sterilizatörlerinde (4/6) biyolojik indikatörlerde pozitiflikler saptandı ve mikrobiyolojik olarak doğrulandı. EO ile sterilizasyon yöntemiyle ise denenen tüm lümen uzunluklarında ve çaplarında negatiflik saptandı (Tablo 1).

\section{TARTIŞMA}

$\mathrm{H}_{2} \mathrm{O}_{2}$ yüksek düzey dezenfeksiyon ve sterilizasyon amacıyla kullanılan geniş spektrumlu ve güçlü okside edici bir ajandır.4 Sıvı formda kullanılacaksa, \%25 üzerinde ki yüksek konsantrasyonlarının sporisidal olduğu unutulmamalıdır. Diğer taraftan, $\mathrm{H}_{2} \mathrm{O}_{2}$ buharı, çok düşük konsantrasyonlarda ( $>0.1 \mathrm{mg} /$ litre) bile sporisidal etki gösterir. ${ }^{2} \mathrm{H}_{2} \mathrm{O}_{2}$, merkezi sterilizasyon ünitelerinde maddenin dördüncü hali olarak da tanımlanan ve elektromanyetik alanlarda üretilen gaz plazma şeklinde kullanılmaktadır. ${ }^{5}$ Plazmada bulunan serbest radikaller hücre membranları, nükleik asitler ve enzimler ile etkileşime girerek hücre fonksiyonlarında bozulma ve mikroorganizmaların ölmesine neden olurlar. ${ }^{6}$

H2O2 GP sistemi ile sterilizasyon yönteminin avantajları; 1sı ve neme hassas malzemeler için uygunluk, sterilizasyon süresinin kısa olması, toksisite yokluğu ve havalandırma gerektirmemesi, malzemeler için kozmetik değişikliğin \%5'in altında olması sayılabilir. ${ }^{5,7,8}$ Lümenli cihazlarda lümen çapı ve uzunluğuna bağlı kısıtlamalar, selüloz, tekstil, pudra ve sıvı sterilizasyonuna uygun olmaması ve nispeten pahalı olması dezavantajlarıdır., ${ }^{5,7}$

EO, tüm mikroorganizmalara etkili, oldukça penetran, renksiz, havadan biraz ağır, çok toksik, patlayıcı ve kan- serojen bir gazdır. Isıya duyarlı malzemelerin sterilizasyonunda etkin güvenlik önlemleri altında yaygın bir şekilde kullanılmaktadır. ${ }^{7}$ Malzeme uyumunun iyi olması, lümenli cihazlar için nispeten uzunluk ve çap kısıtlamasının olmaması avantajlarıdır. Bağımsız havalandırma sistemi olan ayrı bir oda gerektirmesi, sterilizasyon süresinin uzun olması ve uzun havalandırmaya ihtiyaç duyulması, toksik ve kanserojen olması, implantlar, solunum yolunda kullanılacak cihazlar ve emici özelliği fazla olan pamuklu, selüloz içeren vb. malzemeler için uygun olmaması ise dezavantajlarıdır. ${ }^{2,7}$

Ünitemizde bulunan $\mathrm{H}_{2} \mathrm{O}_{2}$ GP sterilizatörlerinden biri olan Sterrad 100S'in metal olmayan (polietilen ve teflon), lümen çapı $\geq 1 \mathrm{~mm}$ ve lümen uzunluğu $\leq 1000 \mathrm{~mm}$ olan cihazlarda kısa ve uzun döngüde booster/adaptör kullanılmadan sterilizasyon yapılabileceği bildirilmektedir. Lümen uzunluğu 1000-2000 mm arasında olan ve $\geq 1 \mathrm{~mm}$ lümen çaplı cihazlarda ise uzun döngüde mutlaka booster/adaptör kullanarak sterilizasyon önerilmektedir. ${ }^{5}$ LK/ MJG-150 $\mathrm{H}_{2} \mathrm{O}_{2}$ GP sterilizatörünün ise, booster/adaptör kullanılmadan toplam uzunluğu $2000 \mathrm{~mm}$ olan, $1 \mathrm{~mm}$ çaplı metal olmayan materyallerden yapılmış lümenli bir cihazı steril edebildiğini bildirmektedir. Son belgelere göre ise, Sterrad NX ve yeni model LK/MJG-150 $\mathrm{H}_{2} \mathrm{O}_{2}$ GP sterilizatörlerinin, $0.7 \mathrm{~mm}$ lümen çaplı ve $850 \mathrm{~mm}$ 'ye kadar uzunluktaki polietilen veya teflon gibi tıbbi cihazların sterilizasyonunu tüm programlarda eksiksiz olarak sağlanacağ firmalar tarafından belirtilmektedir.

EO, düşük sicaklık buhar-formaldehit ve $\mathrm{H}_{2} \mathrm{O}_{2}$ GP yöntemlerinin karşılaştırıldığı bir çalışmada, sterilizasyon- 
dan önce uygun şekilde yıkanamayan uzun, dar lümenli kompleks cihazların sterilizasyonunda $\mathrm{EO}$ ve düşük s1caklık buhar-formaldehit ile sterilizasyona göre ve $\mathrm{H}_{2} \mathrm{O}_{2}$ GP yönteminin yetersiz olabileceği belirtilmektedir. ${ }^{9}$ Dört farklı model Sterrad sterilizatörünün, çeşitli lümen çapı ve uzunluğuna sahip endoskopların steril etmedeki etkinliğinin karşılaştırıldı ğı bir başka çalışmada, kalitatif test sonuçlarına göre, Sterrad 200 ve 100 S sterilizatörlerindeki sterilizasyonun etkinliğinin Sterrad 50 ve 100 sterilizatörlerden daha yüksek olduğu bildirilmektedir. ${ }^{1}$

\section{SONUÇ}

Sonuç olarak, biyolojik indikatör sonuçlarına göre iki farklı H2O2 GP sterilizatörünün karşılaştırıldığı çalışmamızda, her iki sterilizatör ile de yaklaşık olarak benzer sonuçlar elde edildi. Çalışmamızın deneysel koşullarda yapılmış olduğunu, sonucun pratikte, rutin yükte farkll1ık gösterebileceğini de belirtmek isteriz. Ayrıca, indikatörlerin kontrol edildikleri yükte bulunan malzemelerin steril olduklarının kanıtı olmadığı bilinmelidir. Sterilizasyon işleminin etkili olmasının, kontamine olmuş cihazların kapsamlı ve doğrulanmış bir şekilde temizlenmesi, paketleme malzemesi ve yöntemi, paketlerin sterilizatöre uygun şekilde yerleştirilmesi gibi birçok faktöre bağlı olduğu unutulmamalıdır.

Not

Sözlü Sunu olarak sunulmuştur. (11. Uluslararası Dezenfeksiyon ve Sterilizasyon Kongresi 27 Kasım-1 Aralık 2019, Antalya)

\section{Çıkar Çatışması}

Yazarlar çıkar çatışması bildirmemişlerdir.

\section{Finansal Destek}

Yazarlar bu çalışma için finansal destek almadıklarını beyan etmişlerdir.

\section{Etik Kurul Onayı}

Etik kurul izni gerektirmemektedir. 
J Biotechnol and Strategic Health Res. 2020;4(3):272-276

Kaynaklar

1. Okpara-Hofmann J, Knoll M, Dürr M, Schmitt B, Borneff-Lipp M. Comparison of lowtemperature hydrogen peroxide gas plasma sterilization for endoscopes using various Sterrad models. J Hosp Infect 2005; 59(4): 280-5.

2. https://www.das.org.tr/kitaplar/DASRehber2019V10.pdf (sayfa 127)

3. Shintani H. Ethylene oxide gas sterilisation of medical devices. Biocontrol Sci 2017;22(2):1-

4. Wendt $C$, Frei $R$, Widmer AF. Decontamination, disinfection and sterilization. In: Jorgensen JH, Pfaller MA eds. Manual of Clinical Microbiology. 11th editon, Washington DC:ASM Press, 2015:183-216.
5. Günaydın M. Yeni sterilizasyon yöntemleri. ANKEM Derg 2011; 25(Ek 2):170-5.

6. Fichet $G$, Antloga $K$, Comoy $E$ et al. Prion inactivation using a new gaseous hydrogen peroxide sterilisation process, J Hosp Infect 2007; 67(3): 278- 86.

7. Rutala WA, Weber DJ. Disinfection, steriliaztion and antisepsis: An overview. Am J Infect Control 2019; 47S:A3- A9.

8. Sultan N. Yeni sterilizasyon yöntemleri, ANKEM Derg 2006; 20(Ek 2): 84-8

9. Kanemitsu K, Imasaka T, Ishikawa S, et al. A comparative study of ethylene oxide gas, hydrogen peroxide gas plasma, and low-temperature steam formaldehyde sterilization. Infect Control Hosp Epidemiol 2005; 26(5):486-9. 